Minireview

\title{
The contribution of photosynthetic pigments to the development of biochemical separation methods: 1900-1980
}

\author{
Per-Åke Albertsson \\ Department of Biochemistry, Lund University, P.O. Box 124, S-221 00 Lund Sweden \\ (e-mail: per-ake.albertsson@biokem.lu.se; fax: +46-46-2224534)
}

Received 15 August 2002; accepted in revised form 20 December, 2002

Key words: H-E. Åkerlund, P-Å. Albertsson, B. Andersson, aqueous two-phase partition, centrifugation, chloroplast, chromatography, electrophoresis, P. Flodin, S. Hjertén, C. Larsson, J. Porath, T. Svedberg, A. Tiselius, M. Tswett, ultracentrifuge

\begin{abstract}
The role of photosynthetic pigments in the development of separation methods in biochemistry during the period 1900-1980 is described beginning with M. Tswett who introduced separation of chlorophylls and carotenoids on columns and coined the term chromatography in 1906. In Uppsala, T. Svedberg developed the ultracentrifuge in the 1920s. A. Tiselius improved electrophoresis in the 1930s and developed chromatography of proteins in the 1940s and 1950s. Others of 'The Uppsala school in separation science' include J. Porath, P. Flodin and S. Hjertén who further developed various gel chromatographic methods. Hjertén introduced free zone electrophoresis in narrow tubes, a forerunner of capillary electrophoresis. Two proteins, phycoerythrin and phycocyanin, were used as test substances in all these methodological studies. Aqueous two-phase partitioning as a separation method was introduced in 1956 by the author. In this work, chloroplast particles were used, and the method was applied for the separation and purification of intact chloroplasts, inside-out thylakoid vesicles and plasma membranes. My research was carried out in cooperation with G. Blomquist, G. Johansson, C. Larsson, B. Andersson and H.-E. Åkerlund during a 20-year period, 1960-1980.
\end{abstract}

\section{Introduction}

It is well known, and widely appreciated, that biochemical separation methods have played an important role in determining the structure and function of the photosynthetic apparatus. It is perhaps not so well known that the reverse also holds, namely that photosynthetic material has contributed to discoveries and development of methods for biochemical separations.

\section{Chromatography}

Let us begin with the Russian botanist Michail Tswett (1872-1919) who was a pioneer in chromatography (also see Krasnovsky, this issue). He used columns packed with calcium carbonate, inulin or other starch- like powders to separate chlorophyll (Chl) $a$ from $b$ and published this result in 1901. By this procedure he also discovered $\mathrm{Chl} c$ and several xanthophylls. He coined the term 'chromatography' for his method, see the legend to Figure 1.

Tswett's columns were used mainly for low molecular weight substances. In the 1950s there was an increasing interest in applying chromatography to proteins, and several new 'supports' were tried such as ion exchangers, calcium phosphates and different gel particles. Arne Tiselius and co-workers frequently used phycoerythrin and phycocyanin as model proteins for testing various calcium phosphates as column support, leading to several applications of hydroxyapatite (Tiselius et al. 1965) for separating proteins and nucleic acids. Also, in the development 


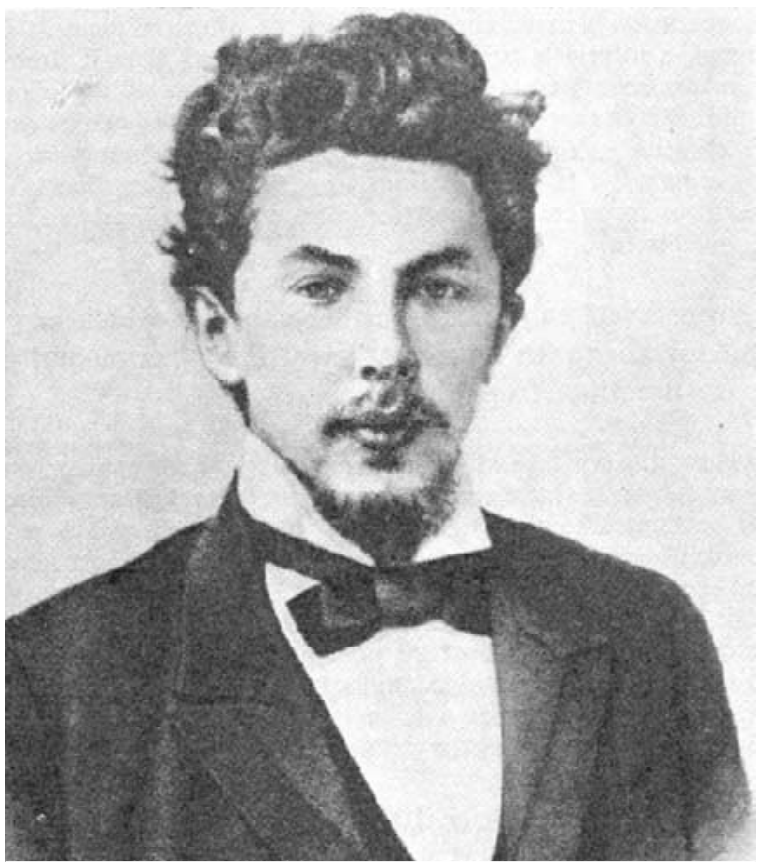

Figure 1. Michail Tswett (1872-1920). His father was Russian and his mother Italian. He studied botany, chemistry and physics in Switzerland (Geneva and Lausanne) and received his doctorate in botany in 1894. In 1901, he moved to Warsaw, Poland where he was a professor of Botany at the University and at the Polytechnic Institute from 1906 until 1917, when he was forced to flee to Russia as a result of the First World War. By this time he was suffering from tuberculosis. In 1918, when he was working at the University of Jurev (now Tartu), Estonia, he again was forced to flee and spent his last years at the University of Voronezj, Russia. In a publication from 1906, he describes a separation of plant pigment on a column of calcium carbonate as follows, translated from the original text in German: 'This separation is made almost complete, if, after the pigment solution is passed down the column, a solvent is passed through the column after it. Just as the light rays in the spectrum are separated, so the various components of the pigment mixture are separated on the calcium carbonate column, and therefore they can be determined qualitatively and quantitatively. This preparation is called a chromatogram and the method is called chromatography,' (Tswett 1906). See also Krasnovsky, this issue.

of gel chromatography, by Jerker Porath, Per Flodin, Stellan Hjertén and co-workers, phycoerythrin and phycocyanin were used as model substances to test the columns and to be able to follow the separation with the naked eye.

\section{Centrifugation}

At the beginning of the 20th century, proteins and other biological macromolecules were not considered as chemically well defined molecules. Rather, they were thought to be colloids, i.e., associations of small molecules. Their aqueous solutions were not molecular solutions but seemingly suspensions like micelles with varying particle size.

In Uppsala, The (Theodor) Svedberg had studied colloidal metals, such as gold sols, and to be able to study small particles he developed a primitive ultracentrifuge in 1923-1924 which he also applied to protein solutions (Svedberg and Lewis 1928). To follow the sedimentation he preferred to use colored proteins such as haemoglobin, phycoerythrin and phycocyanin. The latter were particularly useful since they were strongly colored and had large molecular weights reducing spreading due to diffusion. The remarkable result of these studies was that the proteins behaved as distinct molecules with well defined molecular weights. This prompted improvement of ultracentrifuge technique and studies of several other proteins of a wide span of molecular weights.

Figure 2 shows the sedimentation of phycoerythrin during centrifugation at 39,000 rpm (revolutions per minute). From this and similar studies it was concluded that, to quote, 'the most probable value of the molecular weight of phycoerythrin is 208,000 $\pm 8,000$ and of phycocyanin $106,000 \pm 5,000$, the former within the limits of experimental accuracy, being double the latter. It is interesting to compare these values with those of the other two proteins already investigated in this laboratory, namely, egg albumin and haemoglobin. We have for the molecular weight of egg albumin, 34,500 $\pm 1,000$; for haemoglobin 68,5000 $=34,500 \times 1.99$; for phycocyanin $34,500 \times 3.07$; and for phycoerythrin, $34,500 \times 6.03$ (Svedberg and Lewis 1928). An old sample of phycoerythrin which had been degraded upon standing in the cold room had a molecular weight of around 34,000, i.e., approximately 208,000/6. Based on these results, Svedberg suggested that proteins have molecular weights which are multiples of 17,000 . However, this had to be abandoned later when more molecular weights of different proteins became known.

\section{Electrophoresis}

Arne Tiselius (1902-1971) started his career as research assistant to Svedberg in 1925 and his first two publications concerned work with the ultracentrifuge. Svedberg and Tiselius, Figure 3, realized that the successful approach used for studying proteins by sedimentation in a centrifugal field might also be used 


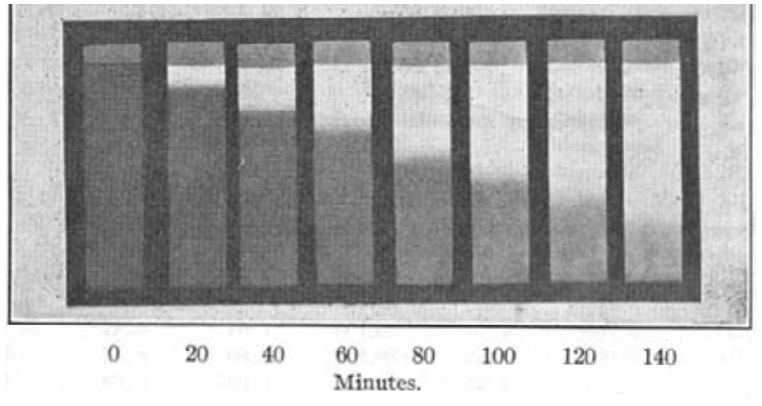

Figure 2. Sedimentation of phycoerythrin from Ceramium rubrum. Photographs of the rotating cell taken during centrifugation at 39,000 rpm, i.e., with a mean centrifugal force of 90, 000 times that of gravity; this photograph is from one of the early experiments with the Svedberg ultracentrifuge carried out in 1927 (Svedberg and Lewis 1928).

for their characterization by movement in an electrical field, i.e., electrophoresis. In his doctoral thesis, published in 1930, Tiselius used phycoerythrin and phycocyanin as model substances for a systematic analysis of both theoretical and experimental aspects of the moving boundary method using a U-tube (Tiselius 1930). This work paved the way for the development of electrophoresis as a reliable method for studying electrophoretic behaviour of proteins. Tiselius' work demonstrated that proteins in solution behaved as molecules having a uniform electrical charge and a well defined isoelectric $\mathrm{pH}$. The breakthrough of the method came when he demonstrated that serum proteins could be separated into four distinct fractions, albumin, alpha -, beta -, and gamma-globulin.

It was probably a great surprise to many colloid chemists at the time when they realized that the results of Svedberg and Tiselius demonstrated that nature had developed macromolecules with well defined particle size and charge. It is of interest that already in 1927 Tiselius separated phycoerythrin and phycocyanin by gel electrophoresis using a bed of gelatin. However, he found the results not interesting enough for publication. In hindsight, this may be considered as a great mistake, perhaps because it delayed the application of gel electrophoresis until after the second World War. However, one should realize that Tiselius at that time, in the1920s, was a graduate student in physical chemistry and, to a physical chemist, electrophoresis in gelatine may not seem to be a very well defined system. Also, perhaps, the time was not then ripe for the scientific community to accept such a highly selective method as gel electrophoresis. Later, in the 1950s and 1960s, Hjertén and co-workers frequently used phy-

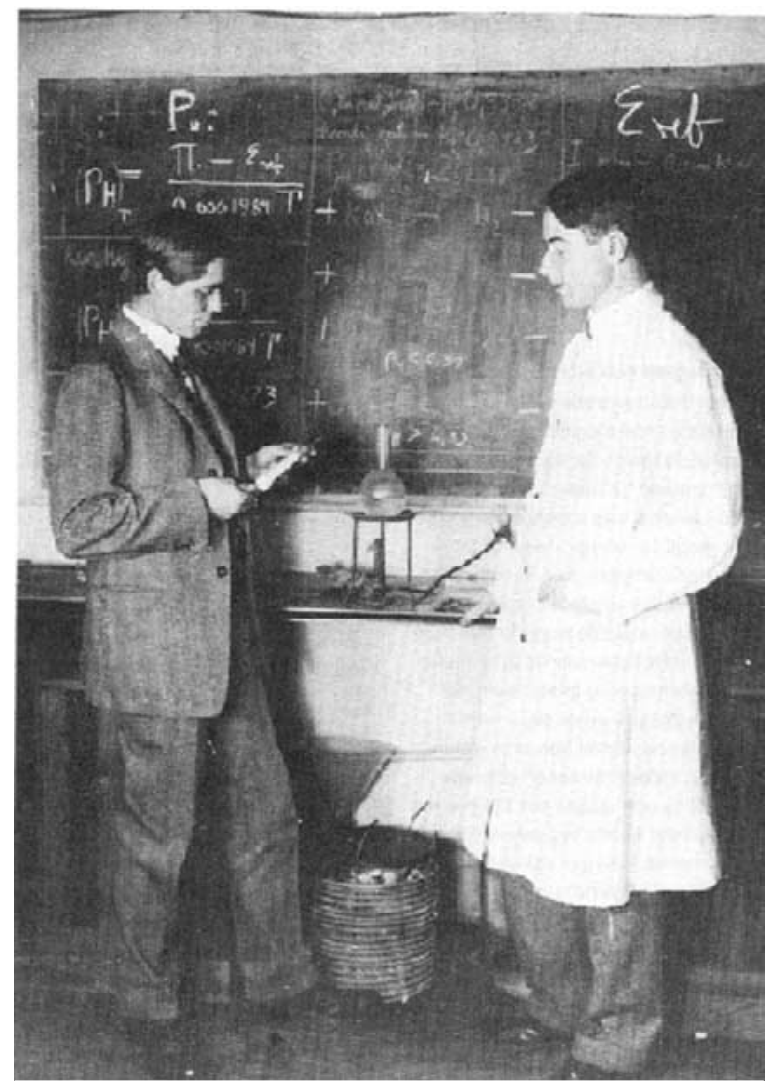

Figure 3. Arne Tiselius (right) started his research career in 1925 as an assistant to The Svedberg (left) in the laboratory of physical chemistry in Uppsala.

coerythrin and phycocyanin as test substances in the development of various gel electrophoresis methods using gels of polyacrylamide and agarose and also for the development of capillary electrophoresis (Hjertén 1958, 1988), Figure 4.

\section{Why phycoerythrin and phycocyanin?}

The advantage of using phycoerythrin and phycocyanin as model proteins for developing biochemical separation methods lies in their strong color; phycoerythrin is red with yellow-orange fluorescence, phycocyanin is blue with orange-red fluorescence. Compared to haemoglobin, phycoerythrin and phycocyanin have many more pigment molecules per given molecular weight of protein; thus, one can use much more dilute protein solutions in the case of phycoerythrin and phycocyanin and yet have strongly colored solutions. This turned out to be important in the case of centrifugation and electrophoresis experiments where 


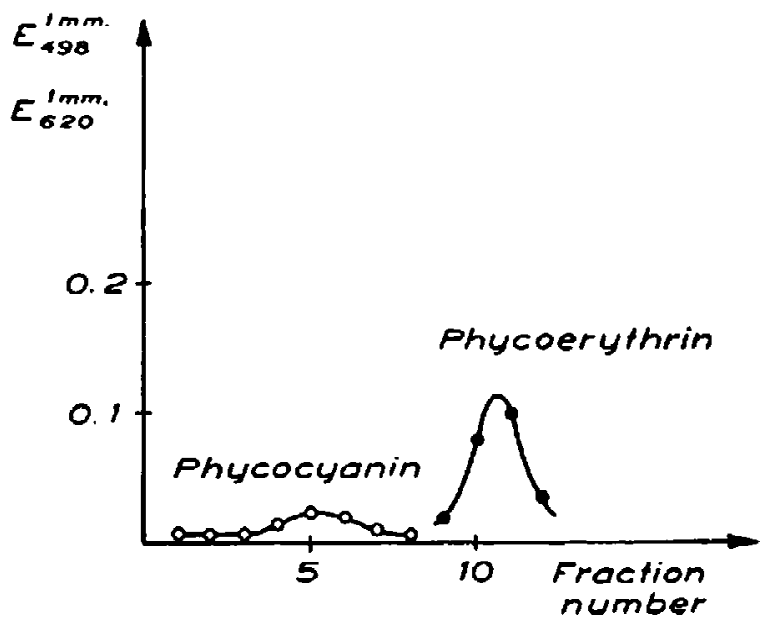

Figure 4. Separation of phycoerythrin from phycocyanin by free zone electrophoresis in a narrow rotating tube designed by Hjertén (1958). His apparatus can be considered as a forerunner of capillary electrophoresis. The terms on the ordinate are absorbance at $498 \mathrm{~nm}$ (phycoerythrin) and at $620 \mathrm{~nm}$ (phycocyanin), respectively.

it is desirable to avoid convection caused by density difference between protein solution and the surrounding, protein-free buffer solution. (Chlorophyll-protein complexes also have a high pigment/protein ratio; light-harvesting complex, LHC II, for example, has about 10 times as many molecules of pigments per unit protein than haemoglobin.)

Both Svedberg and Tiselius had summer houses on the west coast of Sweden in the archipelago of Bohuslän. Tiselius's summerhouse was located not far from Kristineberg's Zoological Station in Fiskebäckskil. Here he had access to large quantities of marine algae. In order to give the reader a flavor of the work to isolate proteins in the 1920 s, I quote the following procedure, described in Tiselius' doctoral thesis, for the isolation of phycoerythrin (Tiselius 1930):

About 20 kilograms (wet) of Ceramium rubrum were collected at Kristinebergs Zoological station, Fiskebäckskil, where the extraction and the first preparation were also carried out. The material was extracted three times with rain-water, each time in a quantity just sufficient to cover the material in the vessel used. The extract was filtered through filter cloth and the material was pressed as much as possible. It was precipitated by addition of $25 \%$ of its weight of ammonium sulphate, The precipitate was filtered and filled in bottles for transport.

Phycoerythrin was further purified and crystallized in Uppsala according to the method of Kylin (1910).

\section{Aqueous two-phase partitioning}

In 1954, I began my graduate studies at the Institute of Biochemistry in Uppsala, the head of which was Arne Tiselius (Figure 5). My supervisor was Håkan Leyon, an electron microscopist who, together with Heitz, had discovered the crystalline-like structure of the prolamellar bodies by electron microscopy (Heitz 1954; Leyon 1954). My first project was to study the structure of Chlorella pyrenoidosa by electron microscopy (Albertsson and Leyon 1954) and then to try to isolate its pyrenoid. Besides centrifugation I also tried chromatography on hydroxylapatite, which had been introduced by Tiselius for separation of proteins (see above). The experiments failed; however, the chloroplast membrane vesicles were easily adsorbed on the columns but could not be eluted even by $1 \mathrm{M}$ phosphate buffer solution. I switched to a batch procedure and attempted to add a detergent in order to elute the particles. I used a solution of polyethylene glycol believing that it was a detergent (which it is not). The combination of high concentration of phosphate buffer together with polyethylene glycol formed a liquidliquid two phase system on top of the hydroxylapatite in the test tube. Furthermore, all the green particles which had been so firmly attached to the apatite were now partitioned into the upper liquid phase containing polyethylene glycol. Due to this spectacular color phenomenon, I realized that partition could be used for the separation of cell particles and macromolecules, which became the theme for my doctoral thesis work (Albertsson 1956, 1958a, 1960). Thus, my using polyethylene glycol, assuming it was a detergent, was a rewarding mistake.

In my thesis work, I frequently used phycoerythrin an phycocyanin in order to study systematically the different factors determining partition of proteins (Albertsson 1958b) in an aqueous-dextran-polyethylene glycol two-phase system. The proteins partitioned according to the Nernst distribution law, i.e., the partition coefficient was independent of the phase volume ratio and protein concentration. This now seems selfevident, but at that time there was a general worry that the polymer-protein interactions might not give an ideal partition behaviour. Phycoerythrin was also used to study the effect of different ions on the partition coefficient (Albertsson and Nyns 1961). Chlorella cells were used for the same purpose to study partition of cells and chloroplasts for studying the partition of cell organelles and membrane vesicles. The partition was independent of the particle concentration and that 


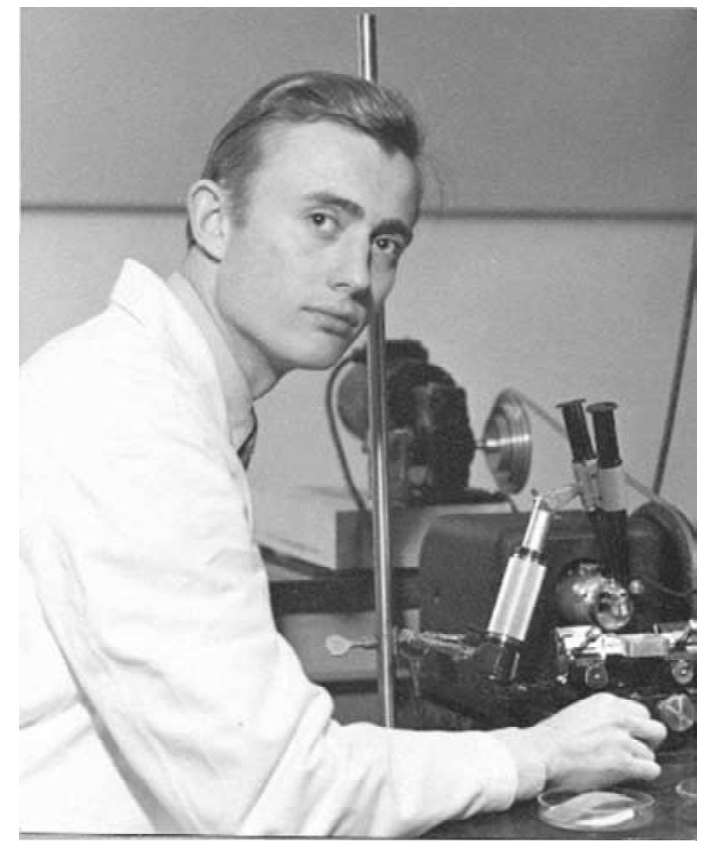

Figure 5. The author (P-A. A.) as a graduate student at the Institute of Biochemistry, Uppsala, in 1954, trying to cut thin sections with an ultramicrotome for electron microscopy of Chlorella pyrenoidosa. The thin sections were then inspected with one of the earliest Siemens electron microscopes brought to the Department of Physical Chemistry during the 1940s by The Svedberg. Photograph taken by Gösta Forsling.

the ratio between the total number (not concentration) of particles in one phase and the number of particles at the interface was constant (Albertsson 1971).

\section{Countercurrent distribution}

Countercurrent distribution is a multiple stage extraction procedure developed by L.C. Craig for the separation of low molecular weight substances using organic solvents. The first countercurrent distribution, using the Craig apparatus, with aqueous polymer phase systems demonstrated that phycoerythrin could be separated from phycocyanin (Albertsson and Nyns 1959). Countercurrent distribution of a phycocyanin preparation gave a diagram that demonstrated that the protein behaved as a single substance and that the technique could be used as an analytical tool for analyzing protein mixtures (Albertsson and Nyns 1959). A thin layer apparatus was developed which allowed a shorter separation time (Albertsson 1965). Countercurrent distribution could also separate cells (Al- bertsson and Baird 1962) and Chlorella pyrenoidosa at different stages of the cell cycle (Walter et al. 1971).

Countercurrent distribution of a chloroplast preparation showed that this consisted of two populations, one representing intact chloroplasts, i.e. with the envelope preserved (class I) and the other representing broken chloroplasts having lost their envelope (class II). (See Walker, this issue, for a discussion of $\mathrm{CO}_{2}$ fixation by intact chloroplasts.) This work was carried out at University of California at Los Angeles (UCLA) together with Herrick Baltscheffsky; it was one of the first isolations of intact chloroplasts (Albertsson and Baltscheffsky 1963). Further, it was demonstrated that in addition to these two populations there was a third population, later named class III, which, in the phase contrast microscope, looked like the intact chloroplasts (Karlstam and Albertsson 1969), Figure 6. By electron microscopy it was found, however, that the class III chloroplasts were surrounded by a cytoplasmic layer, containing mitochondria and peroxisomes, and bounded by the plasma membrane (Larsson et al. 1971). Functional studies by Christer Larsson, Figure 7, and published in his doctoral thesis, showed that these 'multiorganelle particles' could not only fix carbon dioxide and evolve oxygen, but they also synthesize sucrose and amino acids (Larsson and Albertsson 1974).

These class III chloroplast particles had the strongest affinity for the upper phase which demonstrated beautifully how aqueous two-phase partitioning separates particles according to their exposed surface properties. Later, Christer Larsson and coworkers exploited the high affinity of the plasma membrane for the development of a method for isolation and purification of plasma membranes from plant cells which has found many wide applications (Larsson et al. 1994). A similar method is used for isolation of plasma membranes from animal cells (Morré et al. 1994; Persson and Jergil 1994). Covalent binding of bispecific ligands to the polymers allowed the application of various affinity partition methods to the separation of proteins and cell organelles (Johansson 1994; Johansson and Westrin 1978).

The success of the partition method for analyzing chloroplast populations prompted a similar approach on sub-chloroplast vesicles. This study was carried out by Bertil Andersson and Hans-Erik Åkerlund, Figure 8, first in Umeå and then in Lund (Åkerlund et al. 1976; Andersson et al. 1976). After press treatment of stacked thylakoids it could be shown by countercurrent distribution that the sub-thylakoid vesicles were 


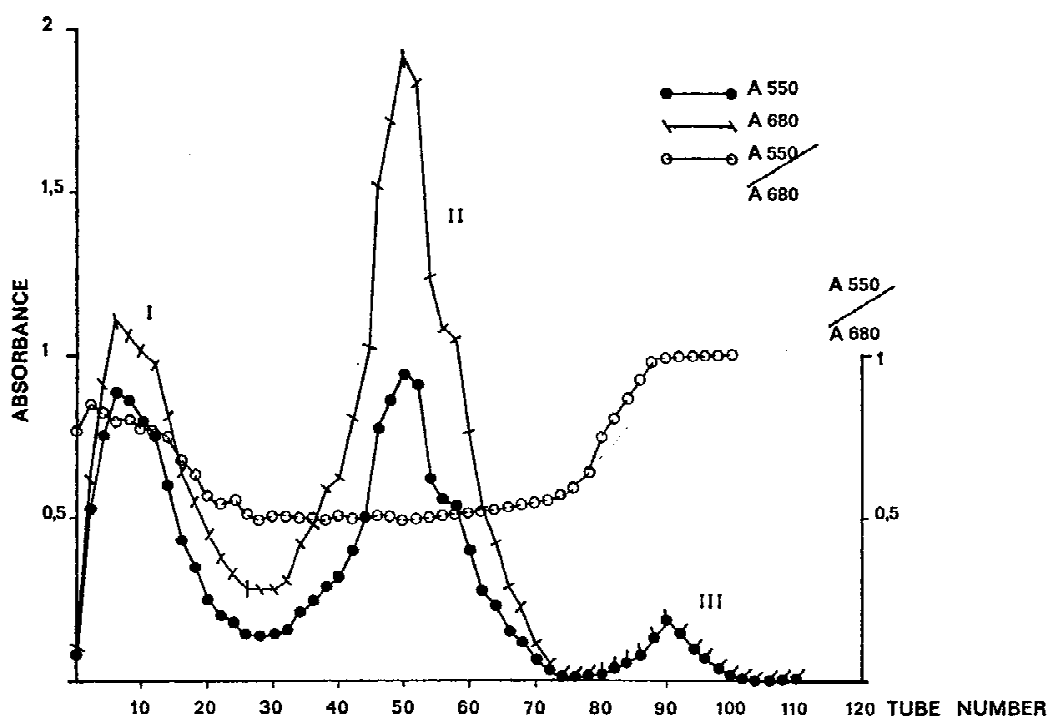

Figure 6. Separation of a conventional chloroplast preparation from spinach into three classes by countercurrent distribution. Peak I represents intact chloroplasts with the envelopes preserved, Peak II represents chloroplasts which have lost the envelope and the stroma and Peak III represents intact chloroplasts embedded in a thin cytoplasmic layer containing cytoplasm, mitochondria, and peroxisomes. The three populations expose different surfaces: I, outer envelope; II, thylakoid membrane; III, plasma membrane.(Karlstam and Albertsson 1969; Larsson et al. 1971).

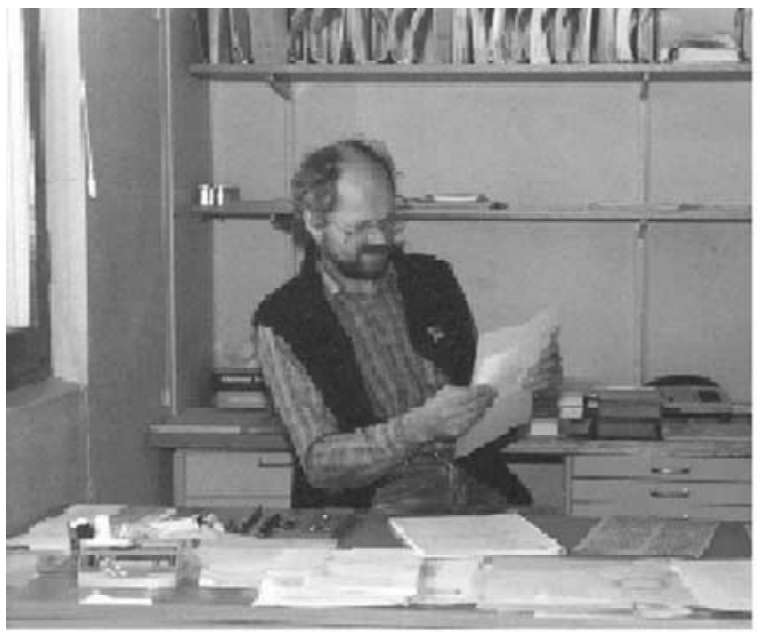

Figure 7. Christer Larsson in his office of the Division of Plant Biochemistry, Chemical Center, Lund University.

very heterogenous which suggested differences in surface properties, Figure 9. This was confirmed by the discovery that one population consisted of inside-out vesicles (originating from the grana) and the other by rightside-out vesicles (Andersson et al. 1977; Andersson and Åkerlund 1978; Åkerlund and Andersson 1983).

One day, Bertil Andersson came into my office and seemed worried: 'Strange, it seems that the left peak (inside-out vesicles) mainly contains PS II and very little PS I'. (At that time, it was generally assumed that the two photosystems were not segregated but intermixed in the grana.) I answered something like, 'Well, let it be so.' I had just read about the patches of bacteriorhodopsin in the purple membrane of Halobacterium halobium and thought that it may not be so strange if PS II also resided in patches in the grana of the thylakoid membrane, which our experiments indicated since the vesicles were of about the same size as the grana partitions.

That inside-out vesicles were enriched in PS II and depleted in PS I suggested a lateral heterogeneity of the thylakoid membrane and in his doctoral thesis (1978), Bertil Andersson presented a model for the thylakoid membrane according to which PS II is confined to the appressed region of the grana while most of the PS I is located in the stroma exposed lamellae. This model was later confirmed by also analyzing the polypeptide composition of the two sub-thylakoid populations (Andersson and Anderson 1980; see Anderson 2002). It is of interest that this model, i.e., PS II in the appressed grana region and PS I in the stroma exposed region, was also suggested by structural arguments from electron microscopic and immunoassay data (Schmid et al. 1976). 

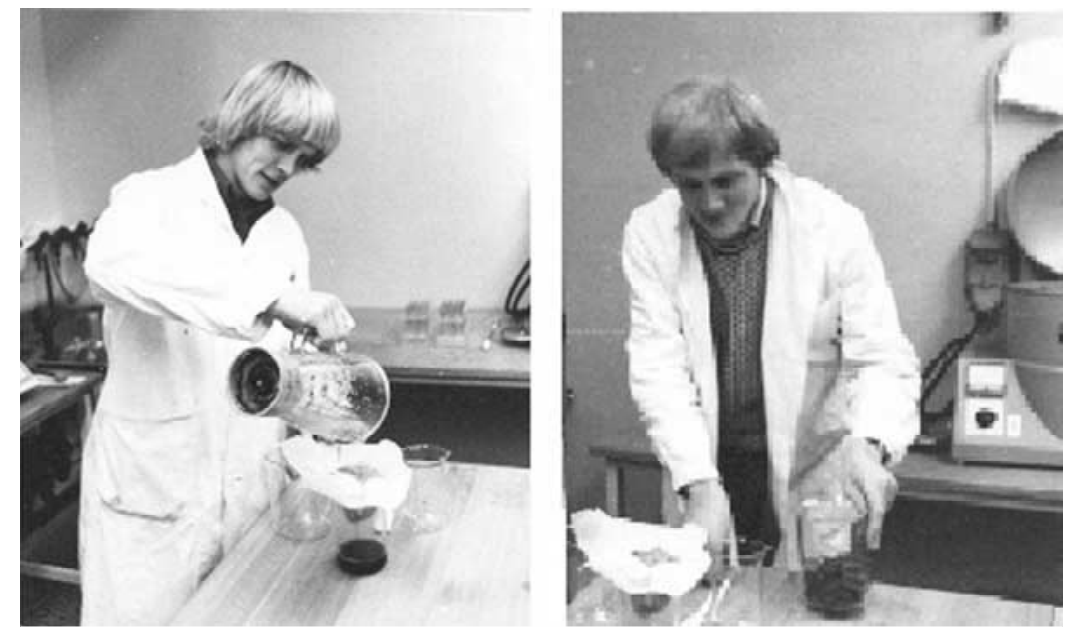

Figure 8. Hans-Erik Åkerlund (left) and Bertil Andersson (right) graduate students preparing spinach chloroplasts for subsequent separation of inside-out from right-side-out thylakoid vesicles. Picture taken by Lars Backman in the cold room of the Biochemistry Department of Umeå University, around 1975.

The inside-out thylakoid vesicles could be used to study the properties of the lumenal surface of the grana and the transverse localization of many proteins. By salt washings, the oxygen evolution was strongly reduced concomitantly with the release from the membrane of two proteins. By lowering the salt concentration and readdition of the released protein, the oxygen evolution was restored. By this procedure Åkerlund and co-workers demonstrated that the oxygen evolution complex is located on the lumenal side of the thylakoid membrane and discovered two proteins (16 and $23 \mathrm{kDa}$ ) essential for the proper functioning of oxygen evolution (Åkerlund et al. 1982).
(For a discussion of oxygen evolution mechanism, see Renger, this issue.)

The success of these fractionation experiments stimulated many other workers to apply aqueous twophase partitioning for the separation and characterization of other biological membranes and cell organelles, of microbial, plant and animal origin, such as plasma membranes, mitochondria, microsomes, synaptosomes, and also whole cells. (The entire volume 228 of Methods in Enzymology, published in 1994, is devoted to applications of the two-phase partitioning technique.) A countercurrent distribution apparatus combined with centrifugation shortened the time for

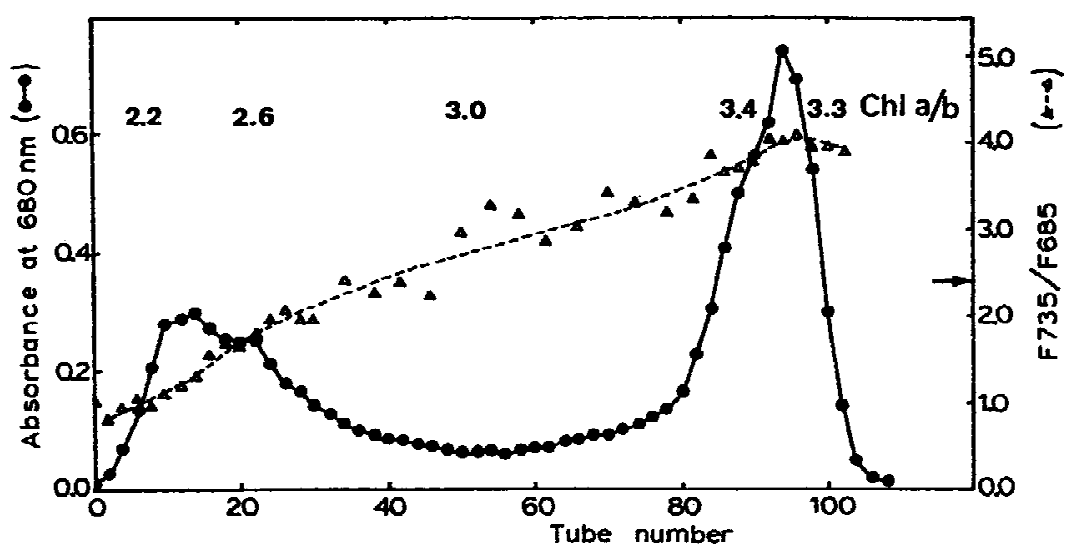

Figure 9. Countercurrent distribution of sub-thylakoid vesicles obtained by mechanical fragmentation of thylakoids from spinach chloroplasts. The left peak is highly enriched in Photosystem II; since these vesicles have a size of about 0.3 microns it was suggested that they originate from Photosystem II regions in the native thylakoid (Åkerlund et al. 1976). In addition the vesicles of the left peak are inside-out while those of the right peak are right-side-out (Andersson et al. 1977). 
phase separation considerably which was essential for the separation of labile cell particles (Åkerlund 1984).

\section{Conclusion}

The use of photosynthetic pigments, particularly the phycobilins in phycoerythrin and phycocyanin, and chlorophyll in chloroplasts and thylakoid fragments have played an important role in the development of biochemical separation methods from the beginning to the end of the 20th century. A rational reason for this is, as I described above, the intense color due to the high concentration of pigments per protein mass. One should not neglect, however, that irrational factors have also been involved: the beauty and natural origin of the protein pigment complexes give an aesthetic touch to the daily work of the researchers. The location of the summer houses of Swedish scientists probably also played a decisive role in selecting phycoerythrin and phycocyanin for work with separation methods.

\section{Acknowledgments}

I thank all students, post docs, visiting scientists and colleagues who have contributed to the development of the phase separation method and for stimulation discussions over the years, notably Hans-Erik Åkerlund, Bertil Andersson, David Baird, Herrick Baltscheffsky, Göran Blomquist, Eva Eriksson, Lars Mörtberg, Shigeru Sasakawa, Vasant Shanbhag, Ingemar Ericsson, Göte Johansson, Björn Karlstam, Christer Larsson, Jaques Nyns, Agneta Persson, George Pinaev, Folke Tjerneld and Harry Walter. This paper was edited by Govindjee.

\section{References}

Åkerlund H-E (1984) An apparatus for counter-current distribution in a centrifugal field. J Biophys Biochem Meth 9: 133-141

Åkerlund H-E and Andersson B (1983) Quantitative separation of spinach thylakoids into Photosystem II-enriched inside-out vesicles and Photosystem I-enriched right-side-out vesicles. Biochim Biophys Acta 725: 34-40

Åkerlund H-E, Andersson B and Albertsson P-Å (1976) Isolation of Photosystem II enriched membrane vesicles from spinach chloroplasts by phase partition. Biochim Biophys Acta 449: $525-535$

Åkerlund H-E, Jansson C and Andersson B (1982) Reconstitution of photosynthetic water splitting in inside-out thylakoid vesicles and identification of a participating polypeptide. Biochim Biophys Acta 681: 1-10
Albertsson P- $\AA$ (1956) Chromatography and partition of cells and cell fragments. Nature 177: 771-774

Albertsson P- $\AA$ (1958a) Particle fractionation in liquid two-phase systems. The composition of some phase systems and the behaviour of some model particles in them. Application to the isolation of cell walls from microorganisms. Biochim Biophys Acta 27: 378-395

Albertsson P- $\AA$ (1958b) partition of proteins in liquid polymerpolymer two-phase systems. Nature 182: 709-711

Albertsson P- $\AA$ (1960) Partition of Cell Particles and Macromolcules, Almquist \& Wiksell, Stockholm John Wiley, New York

Albertsson P-A (1965) Thin layer counter-current distribution. Anal Biochem 11: 121-125

Albertsson P-Å (1971) Partition of Cell Particles and Macromolecules, 2nd ed. John Wiley and Sons, New York

Albertsson P-Å and Baird GD (1962) Counter-current distribution of cells. Exptl Cell Res 28: 296-322

Albertsson P-Å and Baltscheffsky H (1963) Counter current distribution of spinach chloroplasts in an aqueous two-phase system. Biochem Biophys Res Commun 12: 14-20

Albertsson P- $\AA$ and Leyon H (1954) The structure of chloroplasts. V. Chlorella pyrenoidosa Pringsheim studied by means of electron microscopy. Exptl Cell Res 7 288-290

Albertsson P- $\AA$ and Nyns EJ (1959) Counter-current distribution of proteins in aqueous polymer phase systems. Nature 184: 14651468

Albertsson P-A and Nyns EJ (1961) Partition of proteins in an aqueous phase system of dextran and polyethylene glycol. Influence of the electrolyte content. Arkiv Kemi 17: 197-206

Anderson JM (2002) Changing concepts about the distribution of Photosystems I and II between grana appressed and stromaexposed thylakoid membranes. Photosynth Res 73: 157-16

Andersson B (1978) Separation of spinach chloroplast lamellae fragments by phase partition including the isolation of inside-out thylakoids. Doctoral thesis, Lund University

Andersson B and Åkerlund H-E (1978) Inside-out membrane vesicles isolated from spinach thylakoids. Biochim Biophys Acta 503: 462-472

Andersson B and Anderson JM (1980) Lateral heterogeneity in the distribution of chlorophyll-protein complexes of the thylakoid membranes of spinach chloroplasts. Biochim Biophys Acta 593: $427-440$

Andersson B, Åkerlund H-E, and Albertsson P-Å (1976) Separation of subchloroplast membrane particles by counter-current distribution. Biochim Biophys Acta 423: 122-132

Andersson B, Åkerlund H-E and Albertsson P- $\AA$ (1977) Light induced reversible proton extrusion by spinach chloroplast Photosystem II vesicles isolated by phase partition. FEBS Lett 77: $141-145$

Heitz E (1954) Kristallgitterstruktur des granum junger chloroplasten von Chlorophytum. Exptl Cell Res 7: 606-608

Hjertén S (1958) Free zone electrophoresis, preliminary note. Arkiv Kemi 13: 151-152

Hjertén S (1988) The history of the development of electrophoresis in Uppsala. Electrophoresis 9: 3-15

Johansson G (1994) Synaptic membranes. Meth Enzymol 228: 496503

Johansson G and Westrin H (1978) Specific extraction of intact chloroplasts using aqueous biphasic systems. Plant Sci Lett 13: 201-212

Karlstam B and Albertsson P- $\AA$ (1969) Demonstration of three classes of spinach chloroplasts by counter-current distribution. FEBS Lett 5: 360-363 
Krasnovsky Jr AA (2003) Chlorophyll isolation, structure and function: major landmarks of the early history of research in the Russian Empire and the Soviet Union. Photosynth Res 76: 389-403 (this issue)

Kylin (1910) Über Phycoerythrin und Phycocyan bei Ceramium rubrum (Huds.) Ag Z Physiol Chem 9: 169-229

Larsson C and Albertsson P- $\AA$ (1974) Photosynthetic C14carbondioxide fixation by chloroplast populations isolated by a polymer two-phase technique. Biochim Biophys Acta 357: 412-419

Larsson C, Collin C and Albertsson P- $\AA$ (1971) Characterization of three classes of chloroplasts obtained by counter-current distribution. Biochim Biophys Acta 245: 425-438

Larsson C, Sommarin M and Widell S(1994) Isolation of highly purified plant plasma membranes and separation of inside-out and right-side-out vesicles. Meth Enzymol 228: 451-469

Leyon H (1954) The structure of chloroplasts VI. The origin of the chloroplast laminae. Exp Cell Res 7: 609-611

Morré DJ, Reust T and Morré DM (1994) Plasma internal membranes from cultured mammalian cells. Meth Enzymol 228: 448-469

Persson A and Jergil B (1994) Rat liver plasma membranes. Meth Enzymol 228: 489-496
Schmid GH, Jankowicz M and Menke W(1976) Cyclic photophosphorylation and chloroplast structure in the labellum of the orchid Aceras anthropophorum. J Microsc Biol Cell 26: 25-28

Svedberg T and Lewis NB (1928) The molecular weights of phycoerythrin and of phycocyan. J Am Chem Soc 50: 525-536

Tiselius A (1930) The moving boundary method of studying the electrophoresis of proteins. Inaugural dissertation, Uppsala University, Uppsala

Tiselus A, Hjertén S and Lewin Ö (1965) Protein chromatography on calcium phosphate columns. Arch Biochem Biophys 65: 132155

Tswett M (1906) Physikalisch-chemische Studien über das Chlorophyll. Die Adsorptionen. Ber Deutsch Bot Ges 24: 316-323

Walker DA (2003) Chloroplasts in envelopes: $\mathrm{CO}_{2}$ fixation by fully functional intact chloroplasts. Photosynth Res 76: 319-327 (this issue)

Walter H, Eriksson G,Taube Ö and Albertsson P- $\AA$ (1971)Analysis of synchronous and normal populations of Chlorella pyrenoidosa by countercurrent distribution in an aqueous two-polymer phase system. Exp Cell Res 64: 486-490 